\title{
Entrevista a Barbara Lynn Kail
}

\author{
Interview with Barbara Lynn Kail
}

Ma José BARAHONA GOMARIZ

\section{Presentación}

Queremos presentar el perfil de la entrevistada que nos acerque a su ser y hacer en Trabajo Social.

Barbara Lynn Kail es doctora en Bienestar Social, como el paso final de su formación en Trabajo Social, que había iniciado con la obtención del Máster en la Universidad de Columbia.

$\mathrm{Su}$ recorrido como docente se inicia en 1981 y dura hasta la actualidad, pasando por distintas universidades, como la Universidad de Nueva York, de Texas y de Fordham, en las que ha impartido docencia en programas de Máster y Doctorado en Trabajo Social, dirigida a la formación del alumnado en investigación, metodología de la investigación, análisis estadístico, evaluación y política.

Es autora y co-autora de un gran número de publicaciones - artículos y libros - de reflexión y exposición de los hallazgos en las investigaciones en las que participa, que giran en torno a tres ejes, independientes y conexionados entre ellos: el abuso de sustancias, la violencia contra la mujer y el VIH/SIDA.

Pregunta 1: ¿Cuál fue su motivación para estudiar trabajo social?

Respuesta 1: Los años previos a mi entrada en la Universidad marcaron profundamente mi decisión. Crecí en un ambiente rodeado de acción social. Sobre todo me influyó el movimiento de los derechos civiles de los años sesenta, que lo viví durante mi adolescencia.

En aquella época surgen distintos movimientos políticos y sociales, cuyo fin era el reconocimiento de los derechos civiles - fundamentalmente, acabar con la discriminación de las personas afroamericanas - que provocaron cambios en la sociedad; la reivindicación se hizo a través de la desobediencia civil no violenta. En definitiva, se luchaba por el acceso pleno a los derechos civiles y a la igualdad ante la ley de cualquier ciudadano, principalmente de aquellos grupos a los que se les negaban, sobre todo a los ciudadanos negros. Los movimientos de derechos civiles fueron una señal también para el feminismo. El feminismo cambió los roles de las mujeres. Los movimientos de derechos civiles eran la oportunidad para el cambio.

Todo ello me llegó, me emocionó y me llevó a pensar que quería fomentar cambios en la sociedad, pero no sabía de qué manera. Quería defender a las personas, ser un interlocutor válido, por ello en mi futuro se esbozaron dos posibilidades: estudiar Derecho o Trabajo Social. Por rebeldía, por ir contra el sueño de mis padres - que era que estudiara Derecho - elegí Trabajo Social y, así, me matriculé en la Universidad de Columbia en Nueva York, donde obtuve mi titulación.

La carrera fue difícil porque, si bien estaba en la Universidad líder en la educación y la investigación en Trabajo Social, desde 1898, que además era la heredera de la Escuela de Filantropía de Nueva York, los estudios no daban respuesta a mis expectativas: la formación me dirigía hacia el Trabajo Social individualizado, centrado en el problema sustentado en las teorías de Freud y de la Psicología del ego. Así, tuve que buscar una alternativa para encontrar la posibilidad de hacer cambios en las políticas sociales. La encontré en la investigación y me especialicé en ésta y, posteriormente realicé el Doctorado.

Los antecedentes señalados no sólo marcaron mi vida profesional, sino también la personal: adopté a mi hijo afro-americano, siendo madre soltera. Una decisión planificada y iijuna de las mejores que he tomado en mi vida!!!

Pregunta 2: ¿Por qué decidió dedicarse a la docencia universitaria?

Respuesta 2: Porque así podría formar a las nuevas generaciones de trabajadores y trabajadoras sociales con orientación hacia las fortalezas y empoderamiento de los usuarios de los servicios. En la Universidad enseño Metodología de la in- 
vestigación y Política, en los programas de Máster y Doctorado en Trabajo Social, en la Escuela de Servicios Sociales de la Universidad de Fordham, en Nueva York.

Mi decisión de hacer cambios en las políticas, la realizo a través de mis líneas de investigación: el abuso de sustancias en mujeres, especialmente, hispanas y sobrevivientes de la violencia doméstica.

Con el paso de los años, la investigación en Trabajo Social ha cambiado bastante, hoy juega un papel más reconocido y amplio debido a la estrecha relación entre la investigación y la práctica profesional; y como resultado de ello, es el desarrollo de la Práctica Basada en la Evidencia (PBE), realizado en Estados Unidos e Inglaterra y sobre la cual todavía existen muchas voces disidentes; y también el desarrollo de la Política Basada en la Evidencia.

La práctica basada en la evidencia nació en medicina y se ha extendido a otras disciplinas, como el Trabajo Social. La podemos definir como la integración de la mejor evidencia extraída de la investigación y los valores del usuario en la práctica profesional. Es la aplicación de las evidencias, en los niveles micro y mezzo de la práctica profesional. La práctica basada en la evidencia se dirige a la obtención de la triple «e» economía, eficiencia y efectividad - teniendo como protagonista al usuario, respetando sus valores y el derecho a recibir servicios eficaces.

En el nivel superior de aplicación - nivel macro - está la política basada en la evidencia, donde los investigadores - con los resultados de las evidencias encontradas en la revisión sistemática de la literatura profesional- señalan a los políticos en el gobierno las líneas que deben contener las política sociales.

Por todo ello, se resalta la importancia de la investigación, tanto para la disciplina como para la profesión. Se están produciendo cambios en la investigación debido a dos factores. Por una parte, el deseo de los trabajadores y las trabajadoras sociales de elevar su estatus profesional y defender su campo profesional frente al ejercicio de otras disciplinas como la psicología o la enfermería. Por la otra, el creciente interés por la relación entre servicios y resultados, fruto de los recortes económicos y la vuelta a una política de derechas.

Mi aportación desde la universidad es formar a agentes de cambio. Tanto en el Máster como en los cursos de Doctorado, los estudiantes buscan conocimiento: unos para poder acceder a los puestos gubernamentales, dirigiendo políticas públicas; y los otros porque quieren entrar a formar parte de institutos de investigación.

La investigación es un paso imprescindible para proponer y realizar reformas sociales. El que se traslade a políticas sociales depende de distintos factores, siendo el fundamental la ideología de los gobernantes; es decir, la forma de mirar y buscar soluciones. Muchas veces las evidencias no responden o están en consonancia con las posiciones de los políticos; es necesario un acercamiento por parte de los trabajadores sociales. Por otra parte, como crítica, es cierto que las publicaciones de las evidencias están restringidas a los intereses de los profesionales $\mathrm{y}$, por ello, su búsqueda y lectura no son fáciles para quienes no tienen formación ni interés. Parece que hoy en día, los enlaces electrónicos y las redes sociales están acercando estos dos mundos, en tiempos de difusión y en contenidos.

Por todo ello, en las universidades estamos obligadas a impartir formación en investigación de Trabajo Social, exigencia del Council on Social Work Education que es la única agencia acreditada para la educación en Trabajo Social, y que se fundó en 1952. Esta entidad crea y mantiene las normas nacionales de acreditación de la educación e investigación en Trabajo Social.

Pregunta 3. ¿Cómo es el sistema de bienestar en Estados Unidos?

Respuesta 3: El Gobierno Federal fija las líneas de atención y traspasa el dinero, aprobado en los presupuestos anuales a los estados, que son quienes lo administran.

Los gobiernos de los estados no son proveedores de servicios directos, a excepción de la atención a los menores; el resto de ámbitos de intervención son proporcionados por las entidades sin ánimo de lucro subvencionadas por los gobiernos y a través de los seguros privados de salud. En este último caso es lo que se denomina práctica privada.

En Estados Unidos, para poder ejercer como trabajador y trabajadora social es necesario tener un Máster y, posteriormente, superar el examen del Estado. Ello nos proporciona una licencia. En el caso de la práctica privada, una vez obtenida esa licencia y tras haber trabajado con la supervisión de otro trabajador $u$ otra trabajadora 
social durante tres años en una clínica de salud mental, se obtienen una segunda licencia llamada avanzada que posibilita que el seguro médico privado te pague directamente las sesiones que has tenido con su asegurado o asegurada, y no a través de la clínica, como en el caso de la primera licencia.

Pregunta 4: En este sentido ¿todas las universidades deben impartir Máster dado que es requisito para poder ejercer la profesión?

Respuesta 4: Hay distintos niveles para la obtención de tus credenciales formativas, y de acuerde a ellos es como se posibilita el poder trabajar en unos ámbitos, público o privado, y tener un prestigio y un salario acordes con ello.

Una vez acabado lo que en España es el bachillerato, con 18 años, la persona puede ingresar en la Universidad para obtener distintos títulos académicos que pueden ser independientes o consecutivos. En el nivel más bajo, tenemos el «Certificado en Trabajo Social» con una duración de dos años, que se estudia en los «Colleges»; después tenemos el «Bachelor en Trabajo Social», con una duración de cuatro años; luego el Máster con una duración de dos años; y el final de la carrera formativa sería el Doctorado.

Si te das cuenta, para que un o una profesional pueda ejercer en cualquier trabajo y con un salario apropiado, ha de estudiar seis años - Bachelor y Máster - ya que ello te permite presentarte al examen del Estado para poder obtener tu licencia.
Los másteres, por lo general, son de formación generalista, aunque también los hay especializados. En la Universidad de Fordham, donde imparto docencia en el Máster, el primer año es generalista y el segundo es de especialización, en micro o en macro. En los dos años, los estudiantes tienen que cursar de forma obligatoria Política, Investigación y Teoría de la conducta humana.

En Estados Unidos hay muchas universidades, unas son públicas y otras privadas. Dentro de las públicas hay diferencias en relación a distintos criterios, como son: su reconocimiento; su localización - dado que son universidades locales - ; los estudios que imparten. El coste de los estudios — podemos señalar - que parten de una matrícula de 5.000 dólares al año hasta precios más altos, según la Universidad donde se cursen.

Pregunta 5: ¿Cómo ve el futuro del Trabajo Social?

Respuesta 5: Veo el presente que está ligado a recortes económicos, pero que no está quitando la ilusión de las futuras generaciones de una formación y práctica profesional responsable en servicios y resultados.

En Estados Unidos, los profesionales del Trabajo Social, de educación y de enfermería son menos valorados que otros profesionales y la razón fundamental es que mayoritariamente estos profesionales son mujeres. Ese es el estigma. Tenemos que demostrar el doble para ser valoradas. 
